\section{SSC: End of an era}

- he says. Schwitters says that his top priority for now is looking after the 2,000 staff at the SSC laboratory. "Everyone feels a sense of commitment to capturing what we have done", he says. Management at CERN and the SSC are already conferring on how the data can be captured and built upon.

The budget bill due to be passed by Congress this week includes $\$ 640$ million for termination costs at SSC in the coming year, the amount that was to have been spent continuing with the project. This money is supposed to cover restoration of the huge site to its previous state and 90 days' severance plus relocation expenses for the staff, as well as outstanding claims by hundreds of subcontractors.

But Brown says that, once legal settlements with the state of Texas and other likely litigants are included, two years of funding at that level will be needed to wind up the project. That will take the total cost of the debacle to more than $\$ 3$ billion. "It is very difficult for me to perceive why people in their right minds would pursue this course of action", says Brown.

Language in the budget bill requires O'Leary to prepare a report by next July on how to "maximize the value of the investment that has been made". Schwitters says his preliminary understanding is that land restoration will require only that tunnel entrances be closed and made safe, and not that the 15 miles of tunnel already dug be filled in again.

Scientific opponents of the collider were keeping a low profile after the decision. Philip Anderson, professor of particle physics at Princeton University, who has testified in Congress against the project, said he derived no satisfaction from its demise. He declined to comment further; "anything else I say now will be taken as gloating", he says.

But Jocelyn Hong, director of the Washington lobby group OOPS! (Organizations Opposed to the SSC), said the decision would benefit scientists on smaller projects in other disciplines, and noted the generosity of the SSC severance terms. "They get 90 days' money", she says. "No-one else gets that."

Colin Macilwain

\section{SSC: European reaction}

$\checkmark$ community are now certain to campaign for the money to be diverted away from the LHC towards other scientific ends. Others argue that the existence of the SSC made it easier to argue the case for the LHC as a European rival.

On the other hand, the SSC cancellation could also provide an additional impetus for Europe to complete a scientific investigation that is already agreed to be the next logical step for particle physics.

Frank Close, head of theoretical physics at the United Kingdom's Rutherford Laboratory, describes the LHC as now "the only

\title{
Japan fears negative impact on domestic spending
}

Tokyo. The decision by the US Congress to terminate funding for the Superconducting Super Collider (SSC) could have a negative impact on funding for science in Japan, including Japanese participation in the European Laboratory for Particle Physics (CERN).

Since 1990, the United States has been putting pressure on Japan to contribute about $\$ 1.5$ billion to the construction costs of the SSC, a move resented by government officials and scientists in Tokyo.

But the pressure has also helped to make science a political issue in Japan, and has drawn attention to deficiencies in the research system, and in particular the poor state of its universities. Indeed, some Japanese academics fear that cancellation of the SSC could kill attempts to expand the government's budget for science.

Cancellation of the SSC could have a negative impact on negotiations with CERN, says a physicist at Japan's National High Energy Physics Laboratory (KEK), as US pressure for SSC support might have created a new funding mechanism that could

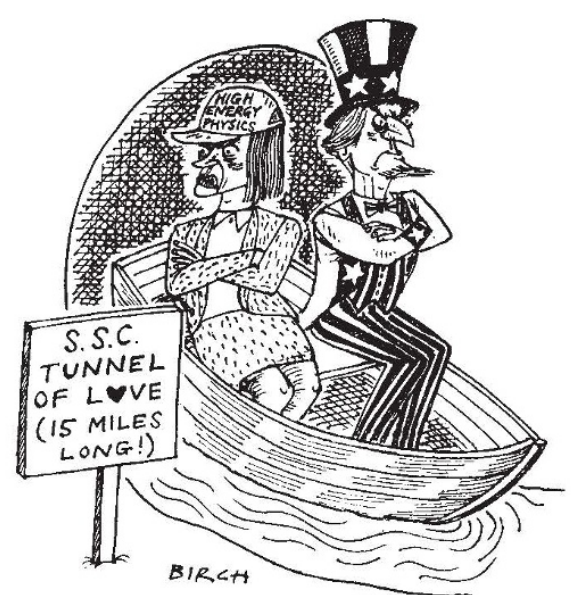

opportunity to access the first moments of the Universe". Furthermore, he says, reaching the scientific goals of the LHC will require achieving a number of significant technological breakthroughs, and this itself will produce numerous benefits.

Both CERN and its member countries are playing their cards close to their chests, unwilling to anticipate the extent of any overrun on the LHC's costs and reactions to it. One solution to both problems would be for the United States to enter a cooperative agreement with CERN, in other words to 'buy in' to the programme. Alison Abbott include a "small channel" to support Japanese participation in CERN. But not everyone shares this view; a university professor involved in CERN negotiations says it is not clear what effect the US decision will have.

But even if the SSC decision helps to clear the way for more decisive negotiations over CERN, there is no guarantee that the Japanese government will have any money to offer. "According to the newspapers many Japanese scientists are quite happy [about SSC decision]", says one science adviser to the Japanese government. "But I worry that it will have a bad effect on the expansion of budgets for basic science."

This adviser complains that Japanese politicians do not understand the difference between the SSC and other high-energy physics projects. As a result, he says, it may now become more difficult to win full funding for KEK's plans for a B-meson factory (see Nature 380, 330; 1993) let alone for CERN, because politicians and the Ministry of Finance are very reluctant to fund new projects in a time of recession.

Japanese supporters of the SSC are trying to make the best of last week's decision. "We are surprised and very disappointed", says Takahiko Kondo of KEK, leader of Japanese participation in the SSC, adding that Japan has "learned a lot" from participation in preparations for the SSC.

Funding from the US-Japan programme on high-energy physics has allowed Japanese scientists to conduct "risky research" that they were not able to do when building the TRISTAN electron positron collider at KEK. As a result, they have developed new superconducting magnets and integrated circuits that will be patented, and will find uses elsewhere in high-energy physics.

Kondo predicts that international competition in $\mathrm{B}$-meson physics will heat up as "US refugees" from the SSC turn to Bmeson physics. But he worries that European governments may "cool" their support of CERN and that this could have an adverse world-wide effect on high-energy physics.

David Swinbanks

\section{Mayor nominated for second UNESCO term}

Paris. The executive board of the United Nations Educational, Scientific and Cultural Organisation (UNESCO) last week nominated Federico Mayor, the Spanish biochemist who is UNESCO's current director general, as its candidate for a second six-year term.

Mayor will be formally elected by the UNESCO general conference on 6 November. 